\title{
Assessment of Determinants of Emission Potentially Affecting the Concentration of Airborne Nano-Objects and Their Agglomerates and Aggregates
}

\author{
Cindy Bekker ${ }^{1,2 *}$, Wouter Fransman ${ }^{2}$, Ruud Boessen², Arné Oerlemans ${ }^{3}$, \\ Ilse B. Ottenbros ${ }^{1}$ and Roel Vermeulen ${ }^{1}$
}

'Division of Environmental Epidemiology, Institute for Risk Assessment Sciences, Utrecht University, The Netherlands; ${ }^{2}$ Risk Analysis for Products in Development, TNO, Zeist, The Netherlands; ${ }^{3}$ Department for Health Evidence, Radboud University Medical Center, Nijmegen, The Netherlands

*Author to whom correspondence should be addressed. Tel: +31610295154; e-mail: cindy.bekker@rivm.nl

Submitted 15 January 2016; revised 14 June 2016; editiorial decision 1 August 2016; revised version accepted 14 November 2016.

\begin{abstract}
Background: Nano-specific inhalation exposure models could potentially be effective tools to assess and control worker exposure to nano-objects, and their aggregates and agglomerates (NOAA). However, due to the lack of reliable and consistent collected NOAA exposure data, the scientific basis for validation of the existing NOAA exposure models is missing or limited. The main objective of this study was to gain more insight into the effect of various determinants underlying the potential on the concentration of airborne NOAA close to the source with the purpose of providing a scientific basis for existing and future exposure inhalation models.

Method: Four experimental studies were conducted to investigate the effect of 11 determinants of emission on the concentration airborne NOAA close to the source during dumping of $\sim 100 \%$ nanopowders. Determinants under study were: nanomaterial, particle size, dump mass, height, rate, ventilation rate, mixing speed, containment, particle surface coating, moisture content of the powder, and receiving surface. The experiments were conducted in an experimental room $\left(19.5 \mathrm{~m}^{3}\right)$ with well-controlled environmental and ventilation conditions. Particle number concentration and size distribution were measured using real-time measurement devices.

Results: Dumping of nanopowders resulted in a higher number concentration and larger particles than dumping their reference microsized powder $(P<0.05)$. Statistically significant more and larger particles were also found during dumping of $\mathrm{SiO}_{2}$ nanopowder compared to $\mathrm{TiO}_{2} / \mathrm{Al}_{2} \mathrm{O}_{3}$ nanopowders. Particle surface coating did not affect the number concentration but on average larger particles were found during dumping of coated nanopowders. An increase of the powder's moisture content resulted in less and smaller particles in the air. Furthermore, the results indicate that particle number
\end{abstract}


concentration increases with increasing dump height, rate, and mass and decreases when ventilation is turned on.

Discussion: These results give an indication of the direction and magnitude of the effect of the studied determinants on concentrations close to the source and provide a scientific basis for (further) development of existing and future NOAA inhalation exposure models.

Keywords: emission determinants; exposure modelling; NOAA; occupational exposure

\section{Introduction}

Exposure models and control banding tools have been developed as pragmatic methods to help companies to prioritize the potential health risks and manage the risks from exposure to a wide variety of potentially hazardous substances. Especially for NOAA (ISO, 2012), where the toxicological and exposure information is scarce and exposure measurements are time consuming and expensive, exposure models and control banding tools could be effective methods to assess and control worker exposure to NOAA.

Currently, a few nano-specific qualitative inhalation tools are publicly available [ANSES (Ostiguy et al., 2010), Control Banding Nanotool (Paik, 2008; Zalk et al., 2009), Precautionary Matrix (Höck et al., 2008), Guidance on working Safely with Nanomaterials (Cornelissen et al., 2011)] and two semi-quantitative tools [Stoffenmanager Nano (van Duuren-Stuurman et al., 2012) and Nanosafer (NRCWE, 2015)]. Based on various determinants, e.g. characteristics of the material, handling, localized controls, segregation, dilution/dispersion etc, these tools categorize both hazard and exposure into different bands indicating the level of risk. Due to a lack of reliable and consistent collected NOAA exposure data, the scientific basis for validation of the underlying exposure models of these tools is missing or limited. Most tools are based on (i) expert judgment, (ii) the assumption that the effect of various determinants on exposure is similar as for micrometer sized particles, and/or (iii) approximated using rotating drum dustiness data. Underpinning and refining the input of different determinants of exposure to NOAA is a key step to get to more scientifically justified and quantitative exposure assessment models.

Schneider et al. (2011) describes a stepwise transfer of a contaminant from the source, through various transmission compartments to the receptor (worker; Schneider et al., 2011). The 'source' compartment of the conceptual model consists of two principal modifying factors: substance emission potential (characteristics of the material) and activity emission potential (emission potential of a material during a particular usage). There are numerous peer reviewed papers describing the results of studies in occupational and experimental settings looking at the potential of release and concentration levels during handling of NOAA or NOAA-containing products (Methner, 2008; Jensen et al., 2009; Tsai, 2010; Rengasamy, 2011; Burdett et al., 2013; Rengasamy, 2013; Tsai, 2013; Bouillard et al., 2014; Rengasamy, 2015; Koivisto, 2015; Levin et al., 2015; Ding and Riediker, 2015). However, only a few studies have looked at the effect of determinants influencing the emission potential by using laboratory bench tests, e.g. dustiness tests (Jensen et al., 2009; Burdett et al., 2013; Bouillard et al., 2014; Ding and Riediker, 2015; Levin et al., 2015). With standard dustiness tests gravimetric results are produced. These dustiness tests already give a good indication of the influence of a certain determinant on the potential of emission. However, there are indications that not mass but number, surface area, and size of the particles provide better insight into the potential hazard of the nanoparticles. So, for nano-hazard, it would potentially be better to study the effect of the determinants in terms of number or surface area concentration and particle size distribution. In standard dustiness tests, the mass concentration is generally measured with gravimetric and chemical analyses of sampled filters. Measuring size distribution, number, and surface area concentration with filter sampling is very complex and time consuming/costly. A more suitable method to measure number or surface area concentration and particle size distribution is with direct reading devices, i.e. less complex, time consuming, and costly. In addition, at the moment, there is no standardized dustiness test for nanomaterials and ranking of the dustiness varies between the different dustiness tests, i.e. rotating drum test, continuous drop (CD) test, vortex shaker etc (Pensis et al., 2010; Tsai et al., 2012; Bach et al., 2013). It is therefore advisable to also study the influence of the determinanton air concentration close to the source in controlled (simulated) workplace situations.

Therefore, the main objective of this studywas to investigate various determinants underlying the substance and activity emission potential with the purpose of providing a scientific basis for existing and future exposure inhalation models. For this purpose, aerosol 
concentrations were measured near the source during four independent experimental studies simulating a dumping processes of $\sim 100 \%$ nanopowder. The experiments are conducted in a controlled environment using various real-time monitoring instruments. In industry, dumping is a common process with nanopowders. In addition, workers are potentially exposed to high NOAA exposure levels which makes dumping of a nanopowder a very relevant process regarding NOAA exposure assessment (Fujitani et al., 2008; Brouwer et al., 2009; Evans et al., 2010; Bekker et al., 2015).

\section{Material and Method}

The dumping experiments were performed in an experimental room of $19.5 \mathrm{~m}^{3}(3.90 \times 2.10 \times 2.38 \mathrm{~m})$ with well-controlled environmental and ventilation conditions (Figure 1). The particle number concentration was measured using a Nanotracer $(\phi 10-300 \mathrm{~nm}$, Philips Aerasense, experiments 1-3) or DiSCmini with impactor ( $\phi 10-700 \mathrm{~nm}$, Matter Aerosol, experiment 4) with a response time of 16 and $1 \mathrm{sec}$, respectively. A Scanning Mobility Particle Sizer (SMPS, $\phi$ 10-500 nm, model 3080, TSI Inc.) and Aerodynamic Particle Sizer (APS, $\phi$ $0.5-20 \mu \mathrm{m}$, model 3321, TSI Inc.) were used to monitor the particle size distribution with a response time of $3 \mathrm{~min}$ and $1 \mathrm{sec}$, respectively. The SMPS and APS were placed outside the room to minimize the influence on the measurement results (e.g. heat production, air flow) and attached to the experimental room with antistatic sampling tubes. The lengths of the tubes were kept to a minimum $(<50 \mathrm{~cm})$ in order to minimize the influence of the tubing on the measurement results. The inlets of the instruments were placed as close to the source as possible $(<30 \mathrm{~cm})$ at dump height (i.e. source compartment).
The controlled circumstances of the experiments allowed a minimal background concentration of $<2000 \# / \mathrm{cm}^{3}$. Background concentrations were measured at the start of each measurement day and before each experiment. In addition, concentration levels were measured during the activity and up to 30 minutes after the activity ended. After each experiment, ventilation was used to bring in filtered air in order to reduce the particle concentration in the room to the initial background concentration level of $<2000 \# / \mathrm{cm}^{3}$. The properties of the nanopowders used (manufactures' data and own measurements) are summarized in Table 1 . The experimental setup and determinants studied per experiment are described below and summarized in Table 2.

\section{Experiment 1: dumping of fumed silica powder}

The first experiment aimed to study the effect of four determinants on the air concentration of NOAA by dumping silica $\left(\mathrm{SiO}_{2}\right)$ powder. Two hydrophilic $\sim 100 \%$ fumed $\mathrm{SiO}_{2}$ powders were used; a $\mathrm{SiO}_{2}$ nanopowder and micropowder with a primary particle size of $10-20 \mathrm{~nm}$ and $2.3 \mu \mathrm{m}$, respectively ('determinant 1 : particle size'). The powders were dumped with two different dumping methods, i.e. single drop (SD) and CD method ('determinant 2: dump rate'). The set-up for the SD method consisted of a tripod with an adjustable top to which a container was connected. In one smooth movement $(3$ seconds) the container was emptied, dumping the powder at once in a metal bowl ( $\varnothing 40 \mathrm{~cm}$, height $=15 \mathrm{~cm}$ ). For the CD method, a Hethon feeder was used to generate a constant dumping rate. The duration of dumping was 10 minutes, resulting in similar amounts dumped by the two methods. In addition, the mass dumped, i.e. 30, 65, and 100 gram ('determinant 3: dump mass') and heights at which the powders were dumped were alternated,

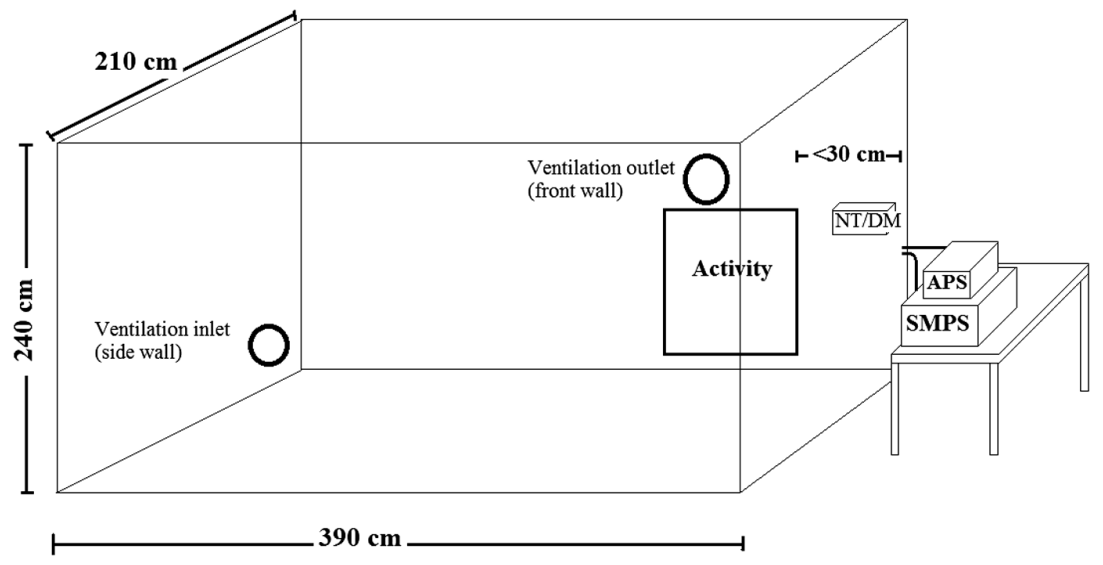

Figure 1. Schematic of the experimental room 


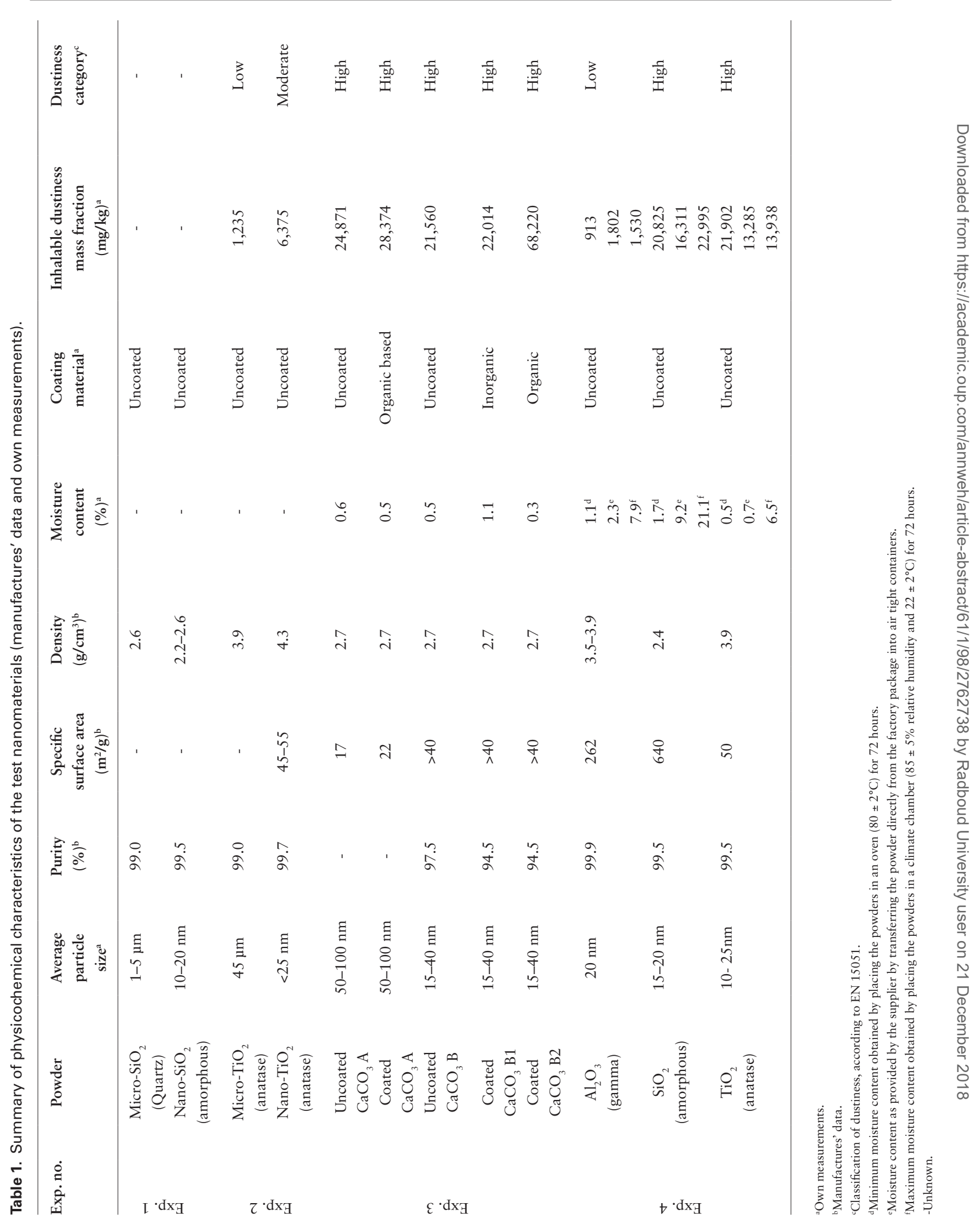


Table 2. Summary determinants and variables.

\begin{tabular}{lc}
\hline Determinant & Variables \\
\hline Nanomaterial & $\mathrm{SiO}_{2} ; \mathrm{TiO}_{2} ; \mathrm{CaCO}_{3} ; \mathrm{Al}_{2} \mathrm{O}_{3}$ \\
Primary particle size & Nano $(10-25 \mathrm{~nm}) ;$ micro $(2.3-45 \mu \mathrm{m})$ \\
Dump mass $(\mathrm{g})$ & $30-400(n=5)$ \\
Dump height $(\mathrm{cm})$ & $5-60(n=5)$ \\
Dump rate & Single drop; continuous drop \\
Ventilation rate $(\mathrm{ACH})$ & $0 ; 13$ \\
Mixing speed $\left(\mathrm{min}^{-1}\right)$ & $36 ; 80$ \\
Containment & Open; closed but breaching system \\
Particle surface coating & Yes; no \\
Moisture content & $0.5-21.1(n=9)$ \\
Receiving surface & Water; container; wallpaper adhesive
\end{tabular}

$\mathrm{ACH}$, air changes per hour.

i.e. 5, 27.5, and $50 \mathrm{~cm}$ ('determinant 4: dump height'). Dump height was defined as the distance relative from the receiving surface (bowl $\varnothing 50 \mathrm{~cm}$, depth $=20 \mathrm{~cm}$ ) to the opening of the container. A D-optimal design was used $(N=27)$ which included 3 repeated experiments. The ventilation in the room was turned off and temperature $\left(24-31^{\circ} \mathrm{C}\right)$ and relative humidity $(45-57 \%)$ were monitored during the experiments.

\section{Experiment 2: dumping and mixing of titanium dioxide powder}

During the second experiment, titanium dioxide $\left(\mathrm{TiO}_{2}\right)$ powders were dumped into a mixing machine containing $20 \mathrm{~L}$ of wallpaper adhesive (to mimic a batch of paint coating). Two $\sim 100 \% \mathrm{TiO}_{2}$ anatase powders were used; a $\mathrm{TiO}_{2}$ nanopowder $(<25 \mathrm{~nm})$ and micropowder $(\leq 45 \mu \mathrm{m}$; 'determinant 1: particle size'). The $\mathrm{TiO}_{2}$ powders were manually dumped at two different rates, i.e. SD (3 seconds) and CD (60 seconds; 'determinant 2: dump rate'). The $\mathrm{TiO}_{2}$ powder was dumped from a plastic bag into the mixing machine. The two different dumping rates were realized by alternating the diameter of the opening in the bag where the powder was dumped through leading to a controlled dump rate. While dumping the $\mathrm{TiO}_{2}$ powder, the blades of the mixing machine were spinning at two different speeds, i.e. 36 and $80 \mathrm{~min}^{-1}$ ('determinant 3: mixing speed'). The safety guard was open or closed during the experiment resulting in an open or closed but breaching system ('determinant 4: containment'). Dump height $(30 \mathrm{~cm})$ and mass $(300 \mathrm{~g})$ were kept constant. General ventilation in the room (HEPA filter, Figure 1) was turned off or on maximum, i.e. 0 or 13 air changes per hour $(\mathrm{ACH}$; 'determinant 5: ventilation'). A D-optimal design was used $(\mathrm{N}=32)$. Temperature $\left(15-26^{\circ} \mathrm{C}\right)$ and relative humidity $(10-41 \%)$ were monitored during the experiments.
Experiment 3: dumping of calcium carbonate nanopowder

Only one determinant was studied in experiment 3; that is, 'particle surface coating'. Five precipitated calcium carbonate $\left(\mathrm{CaCO}_{3}\right)$ nanopowders were selected from two different manufactures. From each manufacturer an uncoated and one (manufacturer A) or two (manufacturer B) surface coated reference (i.e. same core material) $\mathrm{CaCO}_{3}$ nanopowders $(<100 \mathrm{~nm})$ were selected. The initial size of the particles was comparable $50-100 \mathrm{~nm}$ (manufacturer A) and 15-40 nm (manufacturer B). Proprietary details about the particle surface coating were not provided by the manufacturer. Raman Spectroscopy showed that the powders were coated with an organic (coated A and coated B2) or inorganic material (coated B1, Table 1). A Hethon feeder was used to generate a constant dumping rate of $10 \mathrm{~g} / \mathrm{min}$ for 30 minutes ( $300 \mathrm{~g}$ total) at a dump height of $30 \mathrm{~cm}$. The powders were dumped in a metal bowl $(\varnothing 40 \mathrm{~cm}$, height $=15 \mathrm{~cm})$. Each dumping experiment was conducted in triplet $(N=15)$. Temperature $\left(24-30^{\circ} \mathrm{C}\right)$ and relative humidity $(28-49 \%)$ were monitored during the experiments.

Experiment4: dumping of titanium dioxide, aluminum oxide, and silica nanopowder

The effect of 'moisture content' on the air concentration NOAA was studied in a fourth experiment by dumping three nanopowders, i.e. titanium dioxide (anatase, 10-25 nm), aluminum oxide (gamma, $20 \mathrm{~nm}$ ), and silica (amorphous, 15-20 nm), with different moisture contents (minimum, as provided and maximum). A minimum moisture content was obtained by placing the powders in an oven $\left(80 \pm 2^{\circ} \mathrm{C}\right)$ for 72 hours. The maximum moisture content was acquired by placing the powders in a climate chamber $\left(85 \pm 5 \%\right.$ relative humidity and $\left.22 \pm 2^{\circ} \mathrm{C}\right)$ for 72 hours. It was assumed that the change in weight was due to the change in water content. The moisture content was preserved by closing the air-locked containers (6.4 liters, Curtec) immediately after moisturizing and drying, respectively. A part of the powders were transferred from the factory package into containers and directly preserved in order to keep the moisture content as provided by the supplier. The exact moisture content was determined by taking a sample of approximately $5 \mathrm{~g}$ prior to the experiment on a $\%(w / d)$ basis by loss on drying at $102 \pm 2{ }^{\circ} \mathrm{C}$ for 48 hours. The dumping activity simulated a SD, in which 400 gram of nanopowder-based on the weight measured before drying or moisturizing the nanopowders-was dumped at once ( 3 seconds) in a plastic container $(60 \mathrm{~L}$ $\times 50 \mathrm{~W} \times 20 \mathrm{H} \mathrm{cm}$ ). Powders were dumped from two different 'dump heights' $(30 \mathrm{~cm}$ and $60 \mathrm{~cm})$ and onto two different 'receiving surfaces' ( $9 \mathrm{~cm}$ water and no water). 
A full factorial design with eight random replicationswas used $(N=44)$. Temperature $\left(22-30^{\circ} \mathrm{C}\right)$ and relative humidity $(34-58 \%)$ were monitored during the experiments.

\section{Statistical analysis}

A two-stage modelling strategy was used to analyze the data from the various experiments (for a working example see Supplementary information 1, available at Annals of Work Exposures and Health). In the first stage, the data from every individual experiment were analyzed separately. Since these data involved a series of autocorrelated measurements, Autoregressive Integrated Moving Average (ARIMA) models were used for analyzing the time series dataset while taking into account the autocorrelation between the samples. ARIMA models consist out of three parts, the autoregressive (AR)-, moving average (MA)-, and integrated (I)-part. The AR- and MA-part refer to the regression of the concentration (AR) or error term (MA) of a certain time on time lags of itself. An ARIMA model assumes that the time series is stationary. Since the data was not stationary, the data was differenced (I-term) in order to force stationarity (Klein Entink, 2011). Additionally, a second-order moving-average (MA) model, which had the most appropriate fit to the dataset, was applied. Aside from the two autoregression terms, the model included a binary, time-varying regressor that indicated for each time point whether it was a background or activity measurement. This ensured model estimates for the average background concentration as well as the activity-effect (i.e. the average difference in particle number concentration or size between background and activity), while properly accounting for the autocorrelated nature of the data. The activity-effect estimates and their variances (see Supplementary information 2, available at Annals of Work Exposures and Health) were used as input for the second stage of the analysis.

The second stage analysis combined the first stage results per experimental setup in order to estimate the influence of the various determinants on the number concentration and size of the particles emitted in the air, by taking into account the autocorrelation in the time series. It was assumed that the uncertainty in the model estimates is characterized by a log normal model with a mean parameter $(\mu)$ and variance $(\sigma)$ defined by the activity-effect estimates and their variance obtained in the first stage. To adequately account for the uncertainty in model estimates from the first stage, a simulation was conducted. The procedure was as follows: for each measurement, a random value was drawn from the distribution that was defined by the corresponding activity-effect estimate and its variance. These random drawings were analyzed with a multiple linear regression model that included the various determinants as independent variables. This resulted in estimates of the effect that each determinant has on particle number concentration and size, i.e. regression coefficient $(\beta)$ with its standard $(\mathrm{SE})$ and significance $(P<0.05)$. This was repeated 1000 times after which the resulting estimates were pooled in a way that correctly accounted for variance within and between simulation replicates(Rubin, 1987). Model residuals showed some deviations from normality but were considered to be within acceptable limits.

Since the output of the second stage multiple linear regression models were on the log-transformed scale, the regression coefficients were exponentiated, $\operatorname{EXP}(\beta)$, so that the changes in the explanatory variables (i.e. determinants) can be interpreted in terms of multiplicative changes [geometric mean ratio (GMR)] in the dependent variables (i.e. particle number concentration and size). All analyses were performed using the statistical software language R (version 3.1.2; R Foundation for Statistical Computing, Vienna, Austria).

\section{Results}

For each experiment, the GMR, SE, and statistical significance ( $P$ value) of the multiple regression models are shown in Tables 3-6.

\section{Experiment 1: dumping of fumed Silica powder}

The regression model showed a significant relation between the number concentration and the primary particle size of the $\mathrm{SiO}_{2}$ powder (nanopowder or micropowder); i.e. during dumping of $\mathrm{SiO}_{2}$ nanopowders, on average $5.40(1.33, P<0.01)$ times more particles were measured in the air than when dumping a $\mathrm{SiO}_{2}$ micropowder. Although not statistically significant $(P<0.05)$, the results show that dumping a higher mass of powder results in a higher number concentration, i.e. GMR is 1.01 (SE 1.01, $P=0.09$ ) per gram dumped. In addition, dumping a powder at once (SD) instead of dumping a powder over a period time (CD), resulted in 1.66 (1.34, $P=0.08)$ times more particles.

The results indicate that the primary particle size of the $\mathrm{SiO}_{2}$ powder also had an effect on the size of the particles in the air in the upper size range $(\phi 0.5-$ $20 \mu \mathrm{m})$, the average diameter of the particles was 1.11 (1.06, $P=0.08)$ times larger during dumping of $\mathrm{SiO}_{2}$ nanopowders than during dumping $\mathrm{SiO}_{2}$ micropowder. Dump height had no statistically significant effect on the particle number concentration nor on the size of the particles during dumping of $\mathrm{a} \mathrm{SiO}_{2}$ powder (Table 2). 
Table 3. Experiment 1: the effect of theprimary particle size,dump rate, mass, and height on the particle number concentration $\left(\# / \mathrm{cm}^{3}\right)$ and particle size $(\mathrm{nm})$.

\begin{tabular}{|c|c|c|c|c|}
\hline Instrument & Determinant & GMR & SE & $P$ value \\
\hline Number concentration $\# / \mathrm{cm}^{3}$ & Dump rate: $S D$ versus $C D$ & 1.66 & 1.34 & 0.08 \\
\hline \multirow[t]{3}{*}{ (nanotracer, $\phi 10-300 \mathrm{~nm}$ ) } & Primary particle size: nano versus micro & 5.40 & 1.33 & $<0.01$ \\
\hline & Dump mass (per g increase) & 1.01 & 1.01 & 0.09 \\
\hline & Dump height (per $\mathrm{cm}$ increase) & 1.01 & 1.01 & 0.27 \\
\hline \multirow[t]{4}{*}{ Particle size (SMPS, $\phi 10-500 \mathrm{~nm}$ ) } & Dump rate: $S D$ versus $C D$ & 1.05 & 1.18 & 0.78 \\
\hline & Primary particle size: nano versus micro & 1.09 & 1.18 & 0.60 \\
\hline & Dump mass (per g increase) & 1.00 & 1.00 & 0.51 \\
\hline & Dump height (per $\mathrm{cm}$ increase) & 1.00 & 1.00 & 0.98 \\
\hline \multirow[t]{4}{*}{ Particle size (APS, $\phi 0.5-20 \mu \mathrm{m})$} & Dump rate: $S D$ versus $C D$ & 0.98 & 1.06 & 0.76 \\
\hline & Primary particle size: nano versus micro & 1.11 & 1.06 & 0.08 \\
\hline & Dump mass (per g increase) & 1.00 & 1.00 & 0.55 \\
\hline & Dump height (per $\mathrm{cm}$ increase) & 1.00 & 1.00 & 0.31 \\
\hline
\end{tabular}

CD, continuous drop (10 min); SD, single drop (3 sec).

\section{Experiment 2: dumping and mixing of titanium dioxide powder}

During dumping and mixing of $\mathrm{TiO}_{2}$ nanopowder and micropowder in a liquid, very low particle number concentrations were measured, i.e. maximum activity-effect measured was approximately $1000 \# / \mathrm{cm}^{3}$. This was probably due to the fact that the powder was dumped into a liquid and immediately mixed with that liquid hence minimizing the amount of particles emitted. In addition, a relative low amount of materials was dumped. Although not statistically significant, the results show that there are less particles in the air when the ventilation is on than when there is no ventilation used, $\mathrm{GMR}=0.81(1.13, P=0.08)$.

The primary particle size of the $\mathrm{TiO}_{2}$ powder (nanopowder or micropowder) was expected to have a significant effect on the particles in the upper size range $(\phi 0.5-20 \mu \mathrm{m})$, the average diameter of the particles was $1.48(1.12, P<0.01)$ times larger during dumping of $\mathrm{TiO}_{2}$ nanopowders than during dumping $\mathrm{TiO}_{2}$ micropowders. A similar effect was not detected for the lower size range $(\phi 10-500 \mathrm{~nm})$. None of the other variables showed an effect on number concentration or size of the particles (Table 3).

\section{Experiment 3: dumping of calcium carbonate nanopowder}

The presence of a particle surface coating did not significantly affect the particle number concentration when dumping $\mathrm{CaCO}_{3}$ nanopowders. However, handling of coated $\mathrm{CaCO}_{3}$ nanopowders did influence the size of the particles in air in the lower size range $(\phi 10-500 \mathrm{~nm})$; that is, the average diameter of the particles was 1.62
(1.19, $P<0.01)$ times larger during dumping of a coated $\mathrm{CaCO}_{3}$ nanopowder versus an uncoated $\mathrm{CaCO}_{3}$ nanopowder (Table 4). These results were corrected for the effect of the manufacturer (manufacturer A versus B).

\section{Experiment 4: dumping of titanium dioxide, aluminum oxide, and silica nanopowder}

The model showed a significant inverse relation between the moisture content of the powder and the particle number concentration and size $(\phi 10-500 \mathrm{~nm})$ of the particles in the air as a result of dumping nanopowder. An increase of the moisture content decreased the amount and average size of the particles in the air with GMRs of $0.92(1.02, P<0.01)$ and $0.97(1.02, P<0.01)$ per percent increased moisture content, respectively.

There was no difference in number concentration or size of the particles between the dump activities with $\mathrm{TiO}_{2}$ and $\mathrm{Al}_{2} \mathrm{O}_{3}$ nanopowder. However, there was a significant difference in the particle number concentration and the size of the particles in the lower size range $(\phi$ 10-500 nm) as a result of dumping $\mathrm{SiO}_{2}$ nanopowder compared to $\mathrm{TiO}_{2}$ and $\mathrm{Al}_{2} \mathrm{O}_{3}$ nanopowder. Dumping of $\mathrm{SiO}_{2}$ nanopowder resulted in $12.06(1.27, P<0.01)$ times more particles in the air and the average diameter of the particles was $2.36(1.25, P<0.01)$ times larger. In addition, the dump height had a significant effect on the particle number concentration, i.e. the particle number concentration increased with a factor 1.02 (1.01, $P<0.01)$ for every additional centimeter dump height (Table 5). Receiving surface had no significant effect on the number concentration and size of the particles emitted in the air as a result of dumping nanopowders. 
Table 4. Experiment 2: the effect of theprimary particle size,ventilation rate, mixing speed dump rate, and containment on the particle number concentration $\left(\# / \mathrm{cm}^{3}\right)$ and particle size $(\mathrm{nm})$.

\begin{tabular}{|c|c|c|c|c|}
\hline Instrument & Determinant & GMR & SE & $P$ value \\
\hline \multirow{5}{*}{$\begin{array}{l}\text { Number concentration } \# / \mathrm{cm}^{3} \\
\text { (nanotracer, } \phi 10-300 \mathrm{~nm} \text { ) }\end{array}$} & Particle size: nano versus micro & 1.16 & 1.13 & 0.21 \\
\hline & Ventilation rate: 13 versus $0 \mathrm{ACH}$ & 0.81 & 1.13 & 0.08 \\
\hline & Mixing speed:80 versus 36 min $^{-1}$ & 1.11 & 1.13 & 0.37 \\
\hline & Dump rate: $S D$ versus $C D$ & 1.10 & 1.13 & 0.44 \\
\hline & Containment: no versus yes & 0.93 & 1.13 & 0.51 \\
\hline \multirow{5}{*}{$\begin{array}{l}\text { Particle size } \\
\text { (SMPS, ф 10-500 nm) }\end{array}$} & Particle size: nano versus micro & 0.93 & 1.13 & 0.53 \\
\hline & Ventilation rate: 13 versus $0 \mathrm{ACH}$ & 0.91 & 1.13 & 0.44 \\
\hline & Mixing speed: 80 versus $36 \mathrm{~min}^{-1}$ & 1.09 & 1.13 & 0.47 \\
\hline & Dump rate: $S D$ versus CD & 1.00 & 1.13 & 0.99 \\
\hline & Containment: no versus yes & 0.93 & 1.13 & 0.56 \\
\hline \multirow{5}{*}{$\begin{array}{l}\text { Particle size } \\
(\text { APS, } \phi 0.5-20 \mu \mathrm{m})\end{array}$} & Particle size: nano versus micro & 1.48 & 1.12 & $<0.01$ \\
\hline & Ventilation rate: 13 versus $0 \mathrm{ACH}$ & 0.89 & 1.12 & 0.30 \\
\hline & Mixing speed: 80 versus $36 \mathrm{~min}^{-1}$ & 1.07 & 1.12 & 0.52 \\
\hline & Dump rate: $S D$ versus $C D$ & 0.96 & 1.12 & 0.68 \\
\hline & Containment: no versus yes & 1.09 & 1.12 & 0.41 \\
\hline
\end{tabular}

$\mathrm{ACH}$, air changers per hour; CD, continuous drop (60 sec); SD, single drop (3 sec).

Table 5. Experiment 3: the effect of particle surface coating on the particle number concentration $\left(\# / \mathrm{cm}^{3}\right)$ and particle size $(\mathrm{nm})$.

\begin{tabular}{|c|c|c|c|c|}
\hline Instrument & Determinant & GMR & SE & $P$ value \\
\hline Number concentration \#/cm ${ }^{3}$ (nanotracer, $\phi 10-300 \mathrm{~nm}$ ) & Coated versus uncoated & 1.36 & 1.50 & 0.44 \\
\hline Particle size (SMPS, ф 10-500 nm) & Coated versus uncoated & 1.62 & 1.19 & $<0.01$ \\
\hline Particle size (APS, $\phi 0.5-20 \mu \mathrm{m})$ & Coated versus uncoated & 1.06 & 1.07 & 0.40 \\
\hline
\end{tabular}

\section{Discussion}

This study discusses four independent experiments that together investigate the effect of eleven determinants of emission (i.e. substance and activity emission potential) on the number concentration and size distribution of airborne NOAA in close proximity of the source as a result of dumping of $\sim 100 \%$ nanopowders. A well-controlled experimental environment, a consistent method of collecting, and extensive statistical analyses of the data allowed to investigate the effect of the determinants on potential exposure to NOAA near the source and provides a basis for further development and fine tuning of existing and future (quantitative) exposure assessment models and control banding tools.

The results from the multiple linear regression models show a significant difference in emission potential between nanosized and microsized powder, i.e. dumping of nanopowders resulted in a higher particle number concentration and larger particles in the upper size range $(\phi 0.5-20 \mu \mathrm{m})$ than dumping their reference microsized powder. In addition, dumping of $\mathrm{SiO}_{2}$ nanopowders resulted in a higher particle number concentration and larger particle size in the upper size range $(\phi 0.5-20 \mu \mathrm{m})$ than dumping of $\mathrm{TiO}_{2} / \mathrm{Al}_{2} \mathrm{O}_{3}$ nanopowders. Particle surface coating did not have an effect on the number concentration of the airborne particles; however, dumping of coated $\mathrm{CaCO}_{3}$ nanopowders resulted in significant larger particles in the air than dumping of uncoated $\mathrm{CaCO}_{3}$ nanopowders. Also, the results show that an increase of the powder's moisture content resulted in a decrease in the number concentration and size of the airborne particles. Although not statistically significant, there is an indication that particle number concentration increases with increasing dump height, rate, and mass and decreases when general ventilation is turned on. Other determinants investigated in this study, i.e. mixing speed, source containment, and receiving surface, showed no effect on the number concentration nor on the size of the particles in close proximity of the source as a results of dumping of nanopowders. 
Table 6. Experiment 4: the effect of the nanopowder type, moisture content, receiving surface, and dump height on the particle number concentration $\left(\# / \mathrm{cm}^{3}\right)$ and particle size $(\mathrm{nm})$.

\begin{tabular}{|c|c|c|c|c|}
\hline Instrument & Variable & GMR & SE & $P$ value \\
\hline \multirow{4}{*}{$\begin{array}{l}\text { Number concentration \#/cm }{ }^{3} \\
\text { (DiSCmini, } \phi 10-700 \mathrm{~nm} \text { ) }\end{array}$} & NOAA type: $\mathrm{SiO}_{2}$ versus $\mathrm{TiO}_{2}$ and $\mathrm{Al}_{2} \mathrm{O}_{3}$ & 12.06 & 1.27 & $<0.01$ \\
\hline & Moisture content (per \% increase) & 0.92 & 1.02 & $<0.01$ \\
\hline & Receiving surface: water versus dry & 1.29 & 1.20 & 0.16 \\
\hline & Dump height (per $\mathrm{cm}$ increase) & 1.02 & 1.01 & $<0.01$ \\
\hline \multirow[t]{4}{*}{ Particle size (SMPS, $\phi 10-500 \mathrm{~nm}$ ) } & NOAA type: $\mathrm{SiO}_{2}$ versus $\mathrm{TiO}_{2}$ and $\mathrm{Al}_{2} \mathrm{O}_{3}$ & 2.36 & 1.15 & $<0.01$ \\
\hline & Moisture content (per \% increase) & 0.97 & 1.01 & $<0.01$ \\
\hline & Receiving surface: water versus dry & 1.09 & 1.11 & 0.42 \\
\hline & Dump height (per $\mathrm{cm}$ increase) & 1.00 & 1.00 & 0.31 \\
\hline \multirow[t]{4}{*}{ Particle size (APS, $\phi 0.5-20 \mu \mathrm{m})$} & NOAA type: $\mathrm{SiO}_{2}$ versus $\mathrm{TiO}_{2}$ and $\mathrm{Al}_{2} \mathrm{O}_{3}$ & 1.03 & 1.08 & 0.67 \\
\hline & Moisture content (per \% increase) & 0.99 & 1.01 & 0.24 \\
\hline & Receiving surface: water versus dry & 0.96 & 1.06 & 0.47 \\
\hline & Dump height (per cm increase) & 1.00 & 1.00 & 0.39 \\
\hline
\end{tabular}

Burdett et al. (2013) used a rotating drum test to study the effect of particle surface coating on the dustiness of $\mathrm{CaCO}_{3}$ nanopowders (Burdett et al., 2013). Based on gravimetric results, it was concluded that the presence of a particle surface coating substantially increases the inhalable dustiness mass fraction up to a factor 331 . The results of experiment 3 showed that the number concentration during dumping of the coated powder was on average higher than dumping of uncoated powders but in contrary to the results of Burdett et al. (2013) the results were not significant and indicated a GMR of 1.36. Peer reviewed studies show that the various dustiness test methods do not rank dustiness similarly and that the most appropriate method to be chosen depends on the handling process simulated, in our case dumping of nanopowders (Pensis et al., 2010; Tsai et al., 2012; Bach et al., 2013). Therefore, the dustiness of the $\mathrm{CaCO}_{3}$ nanopowders used in experiment 3 was tested in a CD dustiness test. In line with the results of the experimental study, these results showed a (slightly) higher inhalable dustiness mass fraction of the coated $\mathrm{CaCO}_{3}$ nanopowders compared to the uncoated nanopowders (factor 1.14 (manufacturer A) and 1.02-3.16 (manufacturer B), Table 1). Burdett et al. (2013) also showed that the effect of the particle surface coating varied considerably with the type of coating (Burdett et al., 2013). The results of our dustiness tests also show a difference in dustiness between the two different coatings of manufacturer B (Table 1). Unfortunately, detailed information about the type and amount of coating was not provided by the manufacturers limiting the possibility to study the effect of different coating types/amounts in more detail.

Levin et al. (2015) studied the effect of storage conditions such as relative humidity on the dustiness of metal oxide nanopowders using a down-scaled rotating drum test (Levin et al., 2015). The moisture content of the powders increased with increasing relative humidity. In line with the results of experiment 4 , a clear relation between increased moisture content and decreased dustiness was shown (gravimetric data). Unfortunately, due to the discrepancy between methods of analyzing and displaying the results, comparison of the results in terms of multiplicative changes is not possible. Our CD test did not show a clear relation between the moisture content and the dustiness of the powder (Table 1). A reason for this might be the difference between the type of dustiness tests used (rotating drum versus CD test). Levin et al. (2015) also showed that the amount of water uptake is material dependent and probably linked to the surface area of the particles. Our results also show a link between the surface area of the particles and the maximum powder moisture content (Table 1). These results indicate that relative humidity has a clear effect on the potential of nanopowders to generate dust and that the impact of the relative humidity is depending on the surface area of the nanoparticles.

Ding and Riediker (2015) tested the potential of airborne nanoparticle agglomerates to deagglomerate by applying a range of shear forces(Ding and Riediker, 2015). They showed that with increasing shear force, i.e. increasing energy applied, the number concentration and the fraction of particles in the low size range (11$1083 \mathrm{~nm})$ increases and the fraction in the upper size range (0.25-32 $\mu \mathrm{m})$ decreases. Ibaseta et al. (2008) found a significant increase of the particle number concentration with increasing dump height (Ibaseta et al., 2008). In addition, Ibaseta et al. (2008) concluded that the dump height did not effect the particle size distribution. 
Our results did not show a (significant) effect between the number concentration and the amount of energy applied, i.e. mixing speed, receiving surface, dump rate, height, and mass. Nor did we find a significant change in particle size.The results of experiment 4 did not show a difference in number or size of the particles when dumping on a hard surface compared to dumping on a layer of water. However, despite our results it is possible that dumping of nanomaterials in a fluid mix will have a different emission pattern compared to dumping on a hard surface, e.g. due to the bouncing back effect. It can be hypothesized that the range of variables studied per determinant was too limited and potentially not distinctive enough to find significant results. The powders were dumped in only one relatively small layer of water (i.e. $10 \mathrm{~cm}$ ). Relatively small amounts of powder were used during the experiments, i.e. $30-400 \mathrm{~g}$ of material. The amounts used represent laboratory or small scale use and it has to be investigated whether the results found reflect more large scale industrial quantities, i.e. kilos. Dumping heights varied between the 10 and $60 \mathrm{~cm}$ representing the dump heights observed during workplace visits while the dump heights studied by Ibaseta et al. (2008) ranged up to $160 \mathrm{~cm}$ (Ibaseta et al., 2008). Consequently, it is expected that when the energy applied to the process is increased the effect of these determinants become (more) significant.

The measured size distribution of the particles was influenced by particle size, moisture content, particle surface coating, and powder type. Confirming our results, various published studies show that the agglomeration rate increases with decreasing particles size ( $\mathrm{He}$ et al., 2008; Suttiponparnit et al., 2011; Zhou et al., 2013). Theory behind these results is that as the size of the particles decreases, the surface area increases leading to a higher surface energy. In order to minimize its surface energy, agglomerates are formed. Levin et al. (2015) did not observe any change in the particle size distribution between powders with different moisture contents (Levin et al., 2015). Studies investigating the effect of moisture content on dust generation by microsized powders, however, substantiate our results by showing that powders with high moisture content are in a lower state of agglomeration (Plinke et al., 1992; Page, 2000). It is hypothesized that with increasing moisture content the electrical charge of the particles decreases leading to a lower state of agglomeration. In addition, particle surface modification (i.e. coating) may as well have an influence on the electrical charge of the particles leading to a higher or lower state of agglomeration depending on the type of coating. The results presented in this paper give a first indication of the influence of powder characteris- tics on the particle size distribution of NOAA in the air. However, future studies should provide more detailed data supporting these findings to further develop and validate/calibrate risk assessment models.

The results of this study give a first indication of the effect of the studied determinants on the number concentration and size of the emitted NOAA. When generalizing the results we must be aware of the potential limitations and uncertainties. A small number of test materials were used to study the determinants. As the effect of a determinant on the concentration NOAA in the air is potentially influenced by powder properties, it can not automatically generalized to different powders. For example, the effect of particle surface coating on the dustiness levels is influenced by the type of coating (Burdett et al., 2013) and the effect of relative humidity varies considerable between different types of powders (Levin et al., 2015). The experiments conducted in this study all involved a more or less comparable exposure situation. Other exposure situations might lead to other results since factors like use rate, dilution, dispersion, and applied energy have an influence on the results (Ibaseta et al., 2008; Jensen et al., 2009, Levin et al., 2015). The experiments are conducted in an experimental room without ventilation and unmixed air with the measurement point very close to the point of release $(<30 \mathrm{~cm})$ leading to a worst case scenario. In addition, the performance and reliability of the used instruments determine in a large extent the accuracy of the results. Each direct reading instrument currently available has its own (dis)advantages, i.e. size range, response time, working mechanism, etc. The conclusions of the experiments are based on the results of a limited set of instruments and in the future, the conclusions have to be supported by the results of other instruments. For the determinants with continues values, i.e. dump mass, height, rate, etc., proxies were used to estimate the value of the determinants assuming that the determinants behave linearly. However, this assumption may not always hold (Ibaseta et al., 2008; Jensen et al., 2009; Levin et al., 2015). Considering these limitations, the amount of data and diversity has to be increased and the effect of the determinants should be investigated in a broader spectrum in order to adjust the values of the determinant factors of future quantitative inhalation exposure models. In addition, future exposure studies or pooling of published exposure studies should give more insight into the variability of the effects.

The results of experiment 2, dumping and mixing of $\mathrm{TiO}_{2}$ nanopowder, are based on a limited increase of the particle number concentration (maximum activityeffect level was $\sim 1000 \# / \mathrm{cm}^{3}$ ) which may have influenced the assessment of the effect of the determinants. 
The hypothesis is that the limited increase of the particle number concentration is due to the fact that the powder was dumped into a liquid and immediately mixed with that liquid minimizing the amount of particles emitted. However, it has to be noted that this hypothesis should be checked by dumping and mixing powder without a liquid.

In this study, the focus was on the determinants influencing the concentrations airborne NOAA in close proximity of the source. Besides the source characteristics, the occurrence of the NOAA in the breathing zone of the worker will depend on the processes occurring during transport from the source to the receptor, i.e. coagulation/ scavenging, deposition, localized control, segregation/separation, dispersion, and personal behavior. In addition, of NOAA present in the breathing zone of the worker, the actual inhaled concentration NOAA is influenced by the use of personal protective equipment. Although getting an idea about the determinants influencing the concentration of NOAA near the source is important, future studies should also focus on the effect of other determinants potentially influencing the transport of NOAA from the source to the receptor and inhaled concentration as specified by Schneider et al. (2011).

Several quantitative exposure assessment models have been developed for conventional (non-nano-specific) chemicals. The results show that there is a statistically significant difference between the emission potential of nanometer and micrometer sized powders indicating that these non-nano-specific exposure models cannot be used to assess exposure to NOAA in their current state. However, these models might have potential to be extended or adapted for NOAA by calibrating these non-nano-specific exposure models with measured exposure data. Data collected during the experiments could contribute to the further development of such models.

In conclusion, this study provides first indications of the effect of various determinants on the emission potential and therefore on the potential of worker exposure using controlled (simulated) workplace situations. The results of this study provide a scientific basis for (further) development of existing and future nanoexposure inhalation models. Although the results of this study give already a good indication of the significance of various determinants, pooling, and meta-analyses of exposure data from future and available field and experimental studies is important to derive better insight into quantitative exposure modelling across the various life-cycle stages of NOAA.

\section{Supplementary Data}

Supplementary data are available at Annals of Work Exposures and Health online.

\section{Acknowledgements}

This work is supported by NanoNextNL, a micro and nanotechnology consortium of the Government of the Netherlands and 130 partners. The authors would like to thank R. Schimmel for his assistance during the experimental studies.

\section{References}

Bach S, Eickmann U, Schmidt E. (2013) Comparison of established systems for measuring the dustiness of powders with the UNC dustiness tester developed especially for pharmaceutical substances. Ann Occup Hyg; 57: 1078-86.

Bekker C, Kuijpers E, Brouwer DH, et al. (2015) Occupational exposure to nano-objects and their agglomerates and aggregates across various life cycle stages; a Broad-Scale Exposure Study. Ann Occup Hyg; 59: 681-704.

Bouillard J, Henry F, Marchal P. (2014) Rheology of powders and nanopowders through the use of a Couette four-bladed vane rheometer: flowability, cohesion energy, agglomerates and dustiness. J Nanopart Res; 16.

Brouwer D, van Duuren-Stuurman B, Berges M, et al. (2009) From workplace air measurement results toward estimates of exposure? Development of a strategy to assess exposure to manufactured nano-objects. J Nanopart Res; 11: $1867-$ 81.

Burdett G, Bard D, Kelly A, et al. (2013) The effect of surface coatings on the dustiness of a calcium carbonate nanopowder. J Nanopart Res; 15.

Cornelissen R, Jongeneelen F, van Broekhuizen F. (2011) Guidance Working Safely With Nanomaterials and Products, the Guide for Employers and Employees. Amsterdam, The Netherlands: IVAM.

Ding Y, Riediker M. (2015) A system to assess the stability of airborne nanoparticle agglomerates under aerodynamic shear. J Aerosol Sci: 88: 98-108.

Evans DE, Ku BK, Birch ME, et al. (2010) Aerosol monitoring during carbon nanofiber production: mobile direct-reading sampling. Ann Occup Hyg; 54: 514-31.

Fujitani Y, Kobayashi T, Arashidani K, et al. (2008) Measurement of the physical properties of aerosols in a fullerene factory for inhalation exposure assessment. J Occup Environ Hyg; 5: 380-9.

He YT, Wan J, Tokunaga T. (2008) Kinetic stability of hematite nanoparticles: the effect of particle sizes. J Nanopart Res; 10: 321-32.

Höck J, Hofmann H, Krug H. (2008) Precautionary Matrix for Synthetic Nanomaterials. Bern, Switzerland; Federal Office for Public Health and Federal Office for the Environment.

Ibaseta N, Climent E, Biscans B. (2008) SFGP 2007-ultrafine aerosol generation from free falling nanopowders: experiments and numerical modelling. Int J Chem React Eng; 6.

ISO. (2012) ISO /TS 12901-1: Nanotechnologies-Occupational Risk Management Applied to Engineered Nanomaterials. Part 1: Principles and Approaches. ISO/TS 12901-2: Nanotechnologies-Occupational Risk Manage- 
ment Applied to Engineered Nanomaterials. Geneva, Switzerland: International Organization for Standardization.

Jensen KA, Koponen IK, Clausen PA, et al. (2009) Dustiness behaviour of loose and compacted Bentonite and organoclay powders: what is the difference in exposure risk? J Nanopart Res; 11: 133-46.

Klein Entink RH. (2011) How to statistically analyze nano exposure measurement results: using an ARIMA time series approach. J Nanopart Res; 13: 6991-7004.

Koivisto AJ. (2015) Workplace performance of a loose-fitting powered air purifying respirator during nanoparticle synthesis. 17.

Levin M, Rojas E, Vanhala E, et al. (2015) Influence of relative humidity and physical load during storage on dustiness of inorganic nanomaterials: implications for testing and risk assessment. J Nanopart Res; 17.

Methner M. (2008) Effectiveness of local exhaust ventilation (LEV) in controlling engineered nanomaterial emissions during reactor cleanout operations. J Occup Environ Hyg; 5: 63-9.

NRCWE. (2015) NRCWE. Available at http://nanosafer.i-bar. $\mathrm{dk} /$. Accessed web page 2015.

Ostiguy C, Riediker M, Troisfontaines P. (2010) Development of a Specific Control Banding Tool for Nanomaterials. Maisons-Alfort - France: ANSES. French agency for food, environmental and occupational health and safety.

Page SJ. (2000) Relationships between electrostatic charging characteristics, moisture content, and airborne dust generation for subbituminous and bituminous coals. Aerosol Sci Technol; 32: 249-67.

Paik SY. (2008) Application of a pilot control banding tool for risk level assessment and control of nanoparticle exposures. Ann Occup Hyg; 52: 419-28.

Pensis I, Mareels J, Dahmann D, et al. (2010) Comparative evaluation of the dustiness of industrial minerals according to European standard en 15051, 2006. Ann Occup Hyg; 54: 204-16.

Plinke MAE, Maus R, Leith D. (1992) Experimental examination of factors that affect dust generation by using Heubach and MRI testers. Am Ind Hyg Assoc J; 53: 325-30.
Rengasamy S. (2011) Total inward leakage of nanoparticles through filtering facepiece respirators. Ann Occup Hyg; 55: 253-63.

Rengasamy S. (2013) Nanoparticle filtration performance of filtering facepiece respirators and canister/cartridge filters. $J$ Occup Environ Hyg; 10: 519-25.

Rengasamy S. (2015) Protection factor for N95 filtering facepiece respirators exposed to laboratory aerosols containing different concentrations of nanoparticles. Ann Occup Hyg; 59: 373-81.

Rubin DB. (1987) Multiple Imputation for Nonresponse in Surveys. New York: J. Wiley \& Sons.

Schneider T, Brouwer D, Koponen I, et al. (2011) Conceptual model for assessment of inhalation exposure to manufactured nanoparticles. J Expo Sci Environ Epidemiol; 21: 450-63.

Suttiponparnit K, Jiang J, Sahu M, et al. (2011) Role of surface area, primary particle size, and crystal phase on titanium dioxide nanoparticle dispersion properties. Nanoscale Res Lett; 6: 1-8.

Tsai CJ, Lin GY, Liu CN, et al. (2012) Characteristic of nanoparticles generated from different nano-powders by using different dispersion methods. J Nanopart Res; 14.

Tsai CSJ. (2013) Potential inhalation exposure and containment efficiency when using hoods for handling nanoparticles. $J$ Nanopart Res; 15.

Tsai SJ. (2010) Airborne nanoparticle exposures while using constant-flow, constant-velocity, and air-curtain-isolated fume hoods. Ann Occup Hyg; 54: 78-87.

van Duuren-Stuurman B, Vink S, Verbist KJM, et al. (2012) Stoffenmanager Nano version 1.0: a web-based tool for risk prioritization of airborne manufactured nano objects. Ann Occup Hyg; 56: 525-41.

Zalk DM, Paik SY, Swuste P. (2009) Evaluating the control banding nanotool: a qualitative risk assessment method for controlling nanoparticle exposures. J Nanopart Res; 11 : 1685-704.

Zhou D, Ji Z, Jiang X, et al. (2013) Influence of material properties on $\mathrm{TiO}_{2}$ nanoparticle agglomeration. PLOS ONE; 8. 